\title{
Pandemia e vida social: reflexões sobre ciência e sociedade na atual crise global
}

\author{
Pandemic and Social Life: Reflections on Science and \\ Society in the Current Global Crisis
}

\author{
Clarissa Souza de Oliveira \\ McCoy \\ Universidade Estadual do \\ Tocantins, Unitins. \\ University College of Dublin, \\ UCD, Ireland. \\ clarissa.so@unitins.br
}

ORCID: https://orcid.org/00000002-5235-7162

\section{Leila Pereira Dias do Amaral \\ Universidade Estadual do Tocantins, Unitins. \\ dp_amaral@hotmail.com \\ ORCID: https://orcid.org/0000- 0002-5250-7562}

\section{Vinícius Carvalho da Silva \\ Universidade Federal do Mato Grosso do Sul. \\ viniciusfilo@gmail.com \\ ORCID: https://orcid.org/0000- 0002-1061-2727}

\section{Luiz Ricardo Vasconcellos \\ Queen Mary University of London, England.}

luiz.costa1990@gmail.com

ORCID: https://orcid.org/00000002-3877-7013

Data de recebimento: 22/09/2020

Data de aceite: 16/10/2020

\section{Notas introdutórias}

Em face da maior crise sanitária das últimas décadas, pesquisadores da Universidade Estadual do Tocantins decidiram montar um grupo de pesquisa interinstitucional, envolvendo profissionais de diversas áreas, com a finalidade de estudar os impactos da pandemia na vida social das populações atingidas. O tema do grupo é Pandemia e Vida Social: impactos econômicos, políticos, educacionais, saúde mental e culturais (Covid-19/2020). Além das universidades brasileiras parceiras nesse estudo, contamos com a Universidade da Beira Interior-UBI como parceria específica de Acordo de Cooperação. O professor catedrático José Carlos Gaspar Venâncio é o integrante ubiano desse grupo. Dada a amplitude da pandemia, estamos falando de toda a população mundial. Restringir a análise a alguns estados brasileiros, como Tocantins, Pará e Mato Grosso do Sul e um país europeu, Portugal, foi uma necessidade de trabalho, para que o estudo se tornasse viável. A pesquisa está em curso, e nessa oportunidade, não apresentamos resultados, apenas compartilhamos nossos pontos de partida. Como entendemos o momento vivido e a necessidade de melhor compreendê-lo?

Uma de nossas primeiras ações foi organizar uma live com o tema Covid-19: O papel da Ciência nas democracias (UNITINS, 2020), que contou com a participação de alguns dos autores do presente texto. $\mathrm{O}$ encontro permitiu o intercâmbio de ideias entre pesquisadores de diversos campos, como ciências sociais, filosofia política, filosofia da ciência e microbiologia. A seguir, reproduzimos em parte alguns dos tópicos discutidos na ocasião. Tal estrutura nos permitirá apresentar de modo breve e direto o nosso entendimento geral do momento atual, e os desafios de estudá-lo. 


\section{A pandemia de Covid-19}

Em dezembro de 2019 vários relatos hospitalares de pneumonia de etiologia desconhecida foram reportados por hospitais na província de Wuhan, China. Desde então, se iniciou a busca pelo agente causador da doença culminando no isolamento e caracterização de um novo coronavírus causador da síndrome respiratória aguda grave 2, amplamente conhecido por Covid-19. O Covid-19 se espalhou rapidamente por todo o globo em virtude de sua alta taxa de contágio, tendo sido considerado globalmente endêmico no primeiro trimestre de 2020. A pandemia de Covid-19 já acometeu milhões de pessoas e levou ao óbito centenas de milhares ao redor do mundo. Dentre os pacientes que contraem Covid-19 diferentes prognósticos são observados sendo a maioria favorável. Uma parcela desses desenvolvem síndrome respiratória aguda grave que é fortemente relacionada com altas taxas de mortalidade, entretanto.

Para entender as medidas adotadas como estratégia de contenção da disseminação do corona vírus, causador da Covid-19, precisamos entender a biologia dos vírus. Resumidamente, os vírus são estruturas microscópicas relativamente simples e incapazes de automultiplicação, utilizando a maquinaria celular para a produção de novas partículas virais. Em outras palavras, necessitam obrigatoriamente infectar células hospedeiras para a produção de mais vírus e prevalecer na natureza. Desta maneira, como esse vírus necessita células hospedeiras para se reproduzir, a interação social é fundamental para a manutenção e disseminação do mesmo. É importante ressaltar que o Covid-19 foi descoberto recentemente não havendo métodos de prevenção e nem de tratamento comprovadamente efetivos através de terapia medicamentosa. Levando o exposto em consideração, as medidas recomendadas pela Organização Mundial de Saúde se baseiam em romper a cadeia de transmissão através de medidas paliativas de distanciamento social, minimizando assim a circulação do vírus na sociedade. Tais medidas foram sugeridas em virtude do colapso observado nos sistemas de saúde em todos os países afetados pela pandemia. Apesar disso, mesmo com a adoção das medidas de distanciamento social, o referido esgotamento de recursos, físicos e humanos, tem sido o principal desafio sanitário encontrado em virtude da alta demanda por tratamento intensivo e ventilação mecânica no tratamento à pacientes que desenvolvem quadros graves da doença.

\section{A pluralidade do real: um pressuposto para estudarmos a crise atual}

A necessidade de estudos inter e multidisciplinares que abarquem as múltiplas e complexas dimensões da crise alargada pela pandemia de COVID-19 justifica-se pela necessidade de pensar, analisar, compreender esse momento, de buscar dados mais aproximados do que ele realmente representa em termos de mudança social, política, econômica, cultural, e de abordar nosso objeto de estudo a partir de uma perspectiva plural, que leve em conta a abundância da realidade (Feyerabend, 2006). Quais as dimensões em que fomos e somos diretae e indiretamente afetados(as) pela pandemia? Para responder a questões desse tipo precisamos promover o diálogo entre múltiplas formas de saber.

Parcerias entre pesquisadores de múltiplas áreas e instituições diversas trazem à tona a necessidade de pesquisas multirreferenciais sobre um tema comum, no caso a pandemia e seus impactos, mas também, a possibilidade de comparar dados sobre esse tema em regiões próximas e distantes, como Tocantins, Pará e Mato Grosso do Sul, num país com dimensões continentais como é o caso do Brasil. Muitas problematizações se colocam a partir dessa possibilidade: Como tem sido a comercialização de alimentos na pandemia? Em que aspectos tem a pandemia afetado a saúde mental das pessoas? A deflação sofrida no Brasil em geral teve reflexos na economia desses estados pesquisados? O que dizem aqueles(as) que foram vítimas da pandemia e sobreviveram? O isolamento mudou nosso habitus de consumo? Quais os reflexos da negação da ciência para a democracia brasileira? Quais os impactos na cultura de maneira geral? Como a pandemia tem impactado o turismo? A variedade de questões revela que o estudo da pandemia só é possível a partir de uma perspectiva plural e uma abordagem multidisciplinar.

As possibilidades de um estudo comparativo estão postas, observando-se as especificidades de cada linha 
de pesquisa e região a ser estudada. É necessária a interação de pesquisadores Brasil afora e, inclusive, mundo afora, promovendo uma possibilidade de troca de expertise sem limites ou fronteiras físicas ou intelectuais. O momento e o tema pedem a interdisciplinaridade, a possibilidade de criação de novas metodologias e avanço do conhecimento.

\section{Tempos de Crise}

Vivemos um momento profundamente marcado pelo avanço das tecnologias da comunicação e da informação, que tem colocado em contato povos e culturas das mais longínquas partes do mundo, configurando uma sociedade interligada, em rede, conforme Castells (2008). Esse momento é, para Giddens (1991), expresso por uma reflexividade, capaz de desencaixar relações sociais de contextos locais de interação e reestruturá-las em extensões indefinidas de espaço e tempo; vivemos, portanto, o que ele denomina como alta modernidade.

Bauman (2001) afirma que estamos atravessando a modernidade líquida, compreendida pela fluidez cada vez maior das relações sociais, tornando tudo absolutamente transitório e instável. Essa instantaneidade remete as culturas humanas a um território não mapeado e inexplorado, no qual a maioria dos hábitos aprendidos para lidar com a vida cotidiana perderam sua utilidade e sentido. Uma incessante hibridação cultural, no sentido dado por Canclini (2008), está em curso, combinando estruturas e práticas discretas em novas estruturas, objetos e práticas. Afirma-se assim o papel fundamental dado à cultura para a compreensão desse momento chamado contemporaneidade. Que conflitos marcam essa contemporaneidade?

Existe um debate nas ciências sociais, segundo Boaventura de Sousa Santos (2020), sobre se a verdade e a qualidade das instituições de uma dada sociedade podem ser melhor compreendidas em situações de normalidade, de funcionamento corrente, ou em situações controversas, de crise. Quiçá os dois tipos de situação sejam igualmente potencializadoras da produção de conhecimento, mas certamente nos permitem conhecer ou revelar coisas bem diversas. Pergunta Santos (2020): Que potenciais conhecimentos decorrem da pandemia do coronavírus?

A atual pandemia não é, para este autor, uma situação de crise claramente contraposta a uma situação de normalidade. Desde os anos oitenta, quando ocorre uma reestruturação produtiva, à medida que o neoliberalismo foi se impondo como a versão dominante do capitalismo e este foi se adaptando ainda mais à lógica do setor financeiro, o mundo tem vivido em permanente estado de crise.

Por um lado, a ideia de crise permanente é um paradoxo, já que, no sentido etimológico, a crise é, por natureza, excepcional e passageira, e possibilita vislumbrar alguma melhoria futura. Por outro lado, se a crise é passageira, deve ser explicada pelos fatores que a provocam. Mas quando uma crise se torna rotineira, transforma-se na causa que explica todo o resto. A crise financeira permanente é um exemplo disso. Sempre é utilizada para explicar os cortes nas políticas sociais de saúde, educação e previdência social ou as perdas salariais.

Dessa forma, faz-se necessário que se pergunte pelas verdadeiras causas da crise (SANTOS, 2020). Para entendermos a crise, no entanto, assumimos como pressuposto que nossos esforços devem ser plurais e multidisciplinares. Isso significa que a pandemia de Covid-19 é, para Santos (2020), parte de uma crise complexa "multidimensional" cujas raízes se espalham em muitas direções, ponto de vista com o qual concordamos.

\section{Os ataques à democracia e à ciência}

Em nível internacional, vemos a crise da política representativa e das democracias, enfrentamos uma crise ambiental gravíssima, com componentes climáticas e ecossistêmicas radicais, a eleição de líderes com discurso autoritário e agressivo em diversos países revela também uma aguda crise axiológica, isto é, um ataque aos valores humanísticos mais básicos. Nesse quadro de incertezas e desafios, também vemos crises nas ciências, nas universidades e nos mais diferentes campos da cultura. 
Com a empresalização da universidade e a comoditização da ciência os modos de produção do conhecimento sofrem grandes impactos nas últimas décadas. A mentalidade utilitária do tecnocapitalismo subverte o valor e a vocação das universidades e de pesquisadores. Mas os ataques à universidade e às ciências mudaram de figura nessa segunda década do século XXI. O perigo, agora, não é somente o da instrumentalização utilitária, mas, sobretudo, o do negacionismo obscurantista.

As universidades são atacadas como centros de "esquerdismo" e "doutrinação marxista", as ciências negadas e substituídas pelas mais "engenhosas" teorias da conspiração. Esse é o pano de fundo histórico-epistemológico da pandemia de Covid-19. Para compreendermos como a pandemia é gerenciada ou anti-gerenciada globalmente, e mais especificamente, como a pandemia impacta a vida social aqui no cenário doméstico, não podemos deixar de considerar o clima cultural no qual ela ocorre. A negação da ciência faz parte de um "projeto" mais amplo, de ataque às bases da própria democracia.

\section{Em sintese}

Como nossas "considerações finais", destacamos a necessidade de um aprofundamento do que poderíamos chamar de "3 I's", isto é, de colaborações Interdisciplinares, Interinstitucionais e Internacionais, que sejam capazes de superar qualquer distância entre as ciências humanas e as ciências naturais, como as biológicas e biomédicas. Reunir conhecimentos e expertises, promover o diálogo entre profissionais de diferentes áreas, estabelecer colaborações entre instituições do mesmo país e de países diversos, são ações fundamentais para investigarmos eventos e processos complexos como o que enfrentamos atualmente. Nesse pequeno texto, buscamos ressaltar como a questão que constitui o objeto de nossas atenções é plural, possuindo diversas nuances e demandando o diálogo entre múltiplas especialidades. Em síntese, após a pandemia, restará a "possível" distopia de um mundo que serve de palco a muitas crises simultâneas. Tamanho desafio nos exigirá cada vez mais pluralismo, diversidade e colaboração.

\section{Referências}

BAUMAN, Zigmunt. Modernidade líquida. Rio de Janeiro: Jorge Zahar, 2001.

CANCLINI, Nestor García. Culturas híbridas: estratégias para entrar e sair da modernidade. São Paulo: Editora da Universidade de São Paulo - EDUSP, 2008.

CASTELLS, Manuel. A sociedade em rede. 11ª ed. São Paulo: Editora Paz e Terra S/A, 2008.

FEYERABEND, P. K. A conquista da abundância - uma história da abstração versus a riqueza do ser. São Leopoldo: Editora Unisinos, 2006.

GIDDENS, Anthony. As consequências da modernidade. São Paulo: Editora da UNESP, 1991.

SANTOS, Boaventura de Sousa. A cruel pedagogia do vírus. Lisboa: Edições Almedina, 2020.

UNITINS. Live. Canal Unitins no Youtube. 2020. Disponível em: <https://www.youtube.com/watch?v=AECea9d0mF8\&t=429s $>$ Acesso em: 20 de junho de 2020. 